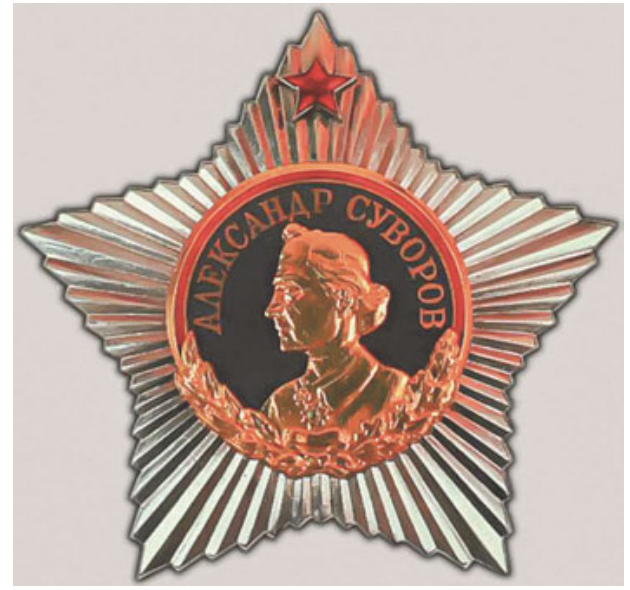

Abb. 1: Suvorov-Orden, 1942. 


\title{
Der Suvorov-Orden (1942/2010) und die Adaptierung einer historischen Heldenfigur für den modernen Massenkrieg
}

\author{
Dietmar Neutatz
}

\section{Einfübrung}

Am 29. Juli 1942, in einer für die Sowjetunion kritischen Phase des Zweiten Weltkriegs, stiftete die sowjetische Regierung den Suvorov-Orden. Namensgeber des Ordens ist Aleksandr Suvorov, ein russischer Feldherr aus dem 18. Jahrhundert. Am selben Tag wurde der Aleksandr-Nevskij-Orden, ein halbes Jahr später der Kutuzov-Orden ${ }^{1}$ gestiftet, beide ebenfalls nach historischen Feldherren benannt.

Fürst Aleksandr Nevskij hatte 1242 in der Schlacht auf dem Eis des Peipussees den Deutschen Orden zurückgeschlagen. General Michail Kutuzov hatte 1812 als Oberbefehlshaber der russischen Truppen im ,Vaterländischen Krieg' gegen Napoleon gesiegt. Aleksandr Suvorov war ebenfalls schon zu Lebzeiten ein gefeierter Feldherr gewesen. Meilensteine seiner Karriere waren der Türkenkrieg 1787 bis 1792, mit dem Russland die Eroberung der Schwarzmeerküste, also der heutigen Südukraine und der Krim vollendete - was für seinen Stellenwert in der gegenwärtigen russischen Erinnerungskultur wichtig ist -, der Kampf gegen die Polen 1794 sowie die Feldzüge in Italien und in den Schweizer Alpen 1799 im Rahmen der Koalitionskriege gegen das revolutionäre Frankreich. Suvorovs Ruhm beruht darauf, dass er keine einzige Schlacht verloren hat. Ihm wird Entschlussfreudigkeit zugeschrieben, verbunden mit unkonventionellen Lösungen abseits starrer Regeln, sowie ein väterlich-fürsorgliches Verhältnis zu seinen Soldaten. In der patriotischnationalistischen Perspektive verkörpert er die russische Kriegskunst, glänzende Siege gegen mächtige Gegner, militärisches Genie, Größe und Macht des Imperiums. $^{2}$

1 Der Kutuzov-Orden wurde am 18. Februar 1943 gestiftet, als die Vernichtung der 6. deutschen Armee in Stalingrad absehbar war.

2 Die Literatur zu Suvorov hat überwiegend heroisierenden Charakter. Aus der Fülle der neueren Darstellungen seien exemplarisch genannt: Peter Hoffmann: Alexander Suworow. Der unbesiegte Feldherr. Berlin 1986; Vjačeslav Lopatin: Suvorov, Moskau 2012; Arsenij Zamost'janov: Velikij Suvorov i suvorovskij obraz v otečestvennoj kul'ture (Der große Suvorov und das Suvorov-Muster in der vaterländischen Kultur), Moskau 2000; Ders.: Suvorov byl neob”jasnimym čudom ... K 275-letiju so dnja roždenija A. V. Suvorova (Suvorov war ein unerklärliches Wunder ... Zum 275. Jahrestag der Geburt Suvorovs), Moskau 2006; Ders.: Aleksandr Suvorov Bog vojny (Aleksandr Suvorov, Gott des Krieges), Moskau 2008; Ders.: Aleksander Suvorov. I žizn' ego polna čudes ... (Aleksandr Suvorov. Auch sein Leben ist voller Wunder ...), Moskau 2012. Ders.: Genij Vojny Suvorov. „Nauka pobeždat'“ (Das Genie des Krieges Suvorov. „Die Wissenschaft zu siegen“), Moskau 2013. Vgl. auch 
Dass in Kriegszeiten militärische Auszeichnungen und Orden verliehen werden, ist nichts Besonderes. Es war damals und ist bis heute bei kriegführenden Staaten übliche Praxis. ${ }^{3}$ Erklärungsbedürftig ist aber, dass ausgerechnet Stalin auf einen Feldherrn des 18. Jahrhunderts zurückgriff, der das zarische Russland verkörperte, wo doch Stalin dem eigenen Land seit 1928 eine radikale Umgestaltung und einen Bruch mit der Vergangenheit aufgezwungen hatte und das alte zarische Russland in der sowjetischen Propaganda als der Inbegriff von Rückständigkeit, Unterdrückung und Unfähigkeit galt. Erklärungsbedürftig ist auch, wie ein Feldherr des 18. Jahrhunderts in der politischen Erinnerungskultur umgemodelt werden musste, um im technisierten Massenkrieg des 20. Jahrhunderts als Vorbild dienen zu können. Ausgehend von dieser Irritation soll im Folgenden gezeigt werden, in welchem Kontext der Orden 1942 gestiftet wurde, wie man einen Feldherrn des 18. Jahrhunderts für die Bedürfnisse des modernen Massenkriegs adaptierte und - um die Brücke in die Gegenwart zu schlagen - welche Rolle der Suvorov-Orden und die Erinnerung an Suvorov 2014 in der Ukraine-Krise spielte.

Den Mittelpunkt des Ordens bildet ein Medaillon mit einem Reliefporträt von Aleksandr Suvorov. Eingerahmt wird das Porträt von zwei Halbkreisen. Den unteren Halbkreis bilden zwei zusammengebundene Zweige mit Lorbeer- und Eichenlaub, die seit der Antike für Sieg beziehungsweise Macht und Treue stehen. Den oberen Halbkreis bildet der Schriftzug mit dem Namen des Feldherrn.

Diese von antiken Vorbildern inspirierte Bildsprache ist eingebettet in sowjetische Symbolik: Der Orden erhält seine Form durch einen Strahlenkranz in Gestalt des fünfeckigen Sowjetsterns. Die oberste Zacke des Sterns ist beim Orden erster Klasse zusätzlich mit einem kleinen roten Sowjetstern versehen. Auf diese Weise erzeugt der Orden eine imaginierte Traditionslinie von der Antike über den russischen Feldherrn des 18. Jahrhunderts bis in die sowjetische Gegenwart.

Der Suvorov-Orden war damals der höchste Militärorden der Sowjetunion. Er wurde in drei Klassen verliehen. Die erste Klasse, aus Platin und Gold, war Kommandeuren von Fronten und Armeen vorbehalten, die zweite Klasse, aus Gold und Silber, konnte an Kommandeure von Korps, Divisionen und Brigaden verliehen werden, die dritte Klasse, aus Silber, an Kommandeure von Regimentern und Bataillonen. Der Orden war also nicht für die Masse der Rotarmisten gedacht, sondern für Offiziere, insbesondere für Generäle und Marschälle. Der

Reinhard Nachtigal: Bricht in Russland ein heroisches Zeitalter an? Der russische Feldherr Alexander Suworow als Kristallisationsfigur eines neuen Nationalmythos. Zu den neuen Biographien von Wjatscheslaw Lopatin und Arsenij Samostjanow, in: helden. heroes. héros. E-Journal zu Kulturen des Heroischen 2, Heft 2, 2014, S. 131-140.

3 Vgl. dazu Ralph Winkle: Für eine Symbolgeschichte soldatischer Orden und Ehrenzeichen, in: Nikolaus Buschmann / Horst Carl (Hrsg.): Die Erfahrung des Krieges. Erfahrungsgeschichtliche Perspektiven von der Französischen Revolution bis zum Zweiten Weltkrieg (Krieg in der Geschichte; 9), Paderborn [u.a.] 2001, S. 195-214; Ders.: Der Dank des Vaterlandes. Eine Symbolgeschichte des Eisernen Kreuzes, 1914-1936, Essen 2007; Ludgera Vogt: Zeichen der Anerkennung. Orden als Medien sozialer Differenzierung und gesellschaftlicher Integration, in: Soziale Welt 48, Heft 2, 1997, S. 187-205. 
Orden wurde in der ersten Klasse $390 \mathrm{Mal}$, in der zweiten Klasse mehr als 2800 $\mathrm{Mal}$, in der dritten Klasse über $4000 \mathrm{Mal}$ verliehen. Den Orden Nummer eins der ersten Klasse erhielt am 28. Januar 1943 Marschall Georgij Žukov. Im Laufe des Krieges wurde ihm der Orden noch zwei Mal verliehen. ${ }^{4}$

\section{Die Adaptierung eines Helden für den modernen Massenkrieg}

Im Sommer 1942 befand sich der Zweite Weltkrieg auf seinem Höhepunkt. Für die Sowjetunion war die Lage prekär geworden. Der Deutschen Wehrmacht war es im Frühjahr 1942 gelungen, nachdem die ursprüngliche Blitzkrieg-Strategie im Herbst 1941 vor Moskau gescheitert war, die Initiative wieder an sich zu reißen und weiter ins Landesinnere vorzustoßen. Angesichts der abermaligen großen Gebietsgewinne der Wehrmacht in Verbindung mit den schweren Verlusten, welche die Rote Armee hatte hinnehmen müssen, und den Einbrüchen in der Lebensmittelversorgung und Industrieproduktion drohte die Sowjetunion zu kollabieren. ${ }^{5}$

Auflösungserscheinungen in der Armee, die an Zustände im Ersten Weltkrieg erinnerten, veranlassten Stalin am 28. Juli 1942 zu dem berüchtigten Befehl Nr. 227 „Keinen Schritt zurück!“. Damit verbot er jeden weiteren Rückzug und drohte allen ,Panikmachern' und ,Feiglingen' mit der sofortigen Exekution oder Versetzung in ein Strafbataillon, die ebenfalls einem Todesurteil gleichkam. Unterstrichen wurde der Befehl durch die Verstärkung der im September 1941 bei den Divisionen aufgestellten Sperrabteilungen, die hinter der Kampflinie auf der Höhe der Artilleriestellungen einen Kordon bildeten und den Auftrag hatten, auf zurückweichende eigene Soldaten zu schießen. ${ }^{6}$

Ähnlich wie schon im Sommer 1941, als die Wehrmacht die Sowjetunion zu überrennen schien, kombinierte Stalin diese repressiv-disziplinierenden Elemente mit dem Appell an den Patriotismus und den Willen der Soldaten, die Heimat und die eigene Familie gegen den eingedrungenen Feind zu verteidigen. Einen Tag nach der Verkündigung des Befehls „Keinen Schritt zurück!“ stiftete das Präsidium des Obersten Sowjet den Suvorov- und den Nevskij-Orden. Die zeitliche Koinzidenz unterstreicht die Verzahnung repressiver und motivierender Elemente im stalinistischen Umgang mit der Bevölkerung. Auf den patriotischen Impetus allein konnte sich Stalin nach all dem Leid, das er Millionen Menschen im eigenen Land seit Ende der 1920er Jahre angetan hatte, nicht verlassen. ${ }^{7}$ Insbesondere die ersten

4 Umfangreiche Informationen samt einer Liste der mit dem Orden ausgezeichneten Personen: https://ru.wikipedia.org/wiki/Орден_Суворова, 17. April 2015. Dietrich Herfurth: Militärische Auszeichnungen der UdSSR, Berlin 1987, S. 56.

5 Richard J. Overy: Russlands Krieg: 1941-1945, übers. von Hainer Kober, Reinbek 2003, S. 243.

6 Ebd., S. 245-250; Joachim Hoffmann: Stalins Vernichtungskrieg: 1941-1945, München 31996, S. 108-109.

7 Für eine eindringliche Schilderung von Stalins Terrorherrschaft siehe Jörg Baberowski: Verbrannte Erde. Stalins Herrschaft der Gewalt, München 2012. 
Kriegsmonate hatten sowohl unter der Zivilbevölkerung als auch in der Roten Armee zu bedenklichen Anzeichen einer Vertrauenskrise geführt. Bis zum Oktober 1941 waren mehr als 650.000 sowjetische Soldaten desertiert, und in der westlichen Ukraine waren die vorrückenden deutschen Verbände als Befreier begrüßt worden. Erst die Erfahrung, dass Hitler einen rücksichtslosen Eroberungs- und Vernichtungskrieg führte, der auf die Dezimierung und Unterwerfung der einheimischen Bevölkerung abzielte, weckte auf breiter Front den Widerstands- und Kampfwillen. Dennoch hegte Stalin stets - und über den gewonnenen Krieg hinaus - ein Grundmisstrauen gegenüber der eigenen Bevölkerung, so dass er zu keinem Zeitpunkt auf die drohende und strafende Gewalt verzichtete. Rotarmisten kämpften nicht nur aus eigenem Antrieb, sondern weil sie wussten, dass hinter ihnen der Tod wartete, sollten sie zurückweichen oder mörderische Angriffsbefehle nicht befolgen. ${ }^{8}$ 158.000 Soldaten wurden während des Krieges zum Tod durch Erschießen verurteilt, eine weitaus größere Zahl wurde ohne Gerichtsverfahren erschossen, 436.000 wurden verhaftet, 422.000 landeten in Strafeinheiten. Keine andere Armee des Zweiten Weltkriegs ging so rücksichtslos gegen ihre eigenen Soldaten vor. ${ }^{9}$

Daneben gab es aber eben auch die auf intrinsische Motivationen setzende Strategie. Die Ordensstiftungen waren geschichtspolitische Signale ersten Ranges, denn mit ihnen verabschiedete sich die Führung von der internationalistischen Legitimation und wandte sich demonstrativ den Kriegshelden der russischen Geschichte zu. In überhöhter Parallele zum ,Vaterländischen Krieg' von 1812 gegen Napoleon wurde der Krieg jetzt endgültig zum ,Großen Vaterländischen Krieg. ${ }^{6}{ }^{10}$ Es ging darum, alle Kräfte im Existenzkampf gegen die einen Eroberungs- und Vernichtungskrieg führenden Deutschen zu mobilisieren. Zu dieser patriotischen Mobilisierung gehörte unter anderem die Rückbesinnung auf die Traditionen der zarischen Armee und eine Aufwertung der Offiziere. Damit vollzog Stalin eine Kehrtwendung, denn bis dahin hatte er den militärischen Führern misstraut. Im Großen Terror hatte Stalin 1937/38 das höhere Offizierskorps der Roten Armee dezimiert. ${ }^{11} \mathrm{Um}$ die durch diesen empfindlichen Aderlass erzeugte Führungsschwäche zu kompensieren und die strikte Befolgung der von oben kommenden Durchhalte-

8 Vgl. ebd., S. 412-435. Für das Zusammenspiel der repressiven und motivierenden Elemente siehe auch Dietmar Neutatz: Träume und Alpträume. Eine Geschichte Russlands im 20. Jahrhundert (Europäische Geschichte im 20. Jahrhundert), München 2013, S. 286-300.

9 Orlando Figes: Die Flüsterer. Leben in Stalins Russland, ${ }^{3 B}$ Berlin 2008, S. 590-591; Catherine Merridale: Iwans Krieg: Die Rote Armee 1939 bis 1945, übers. von Hans Günter Holl, Frankfurt am Main 22006, S. 176-179; Jurij A. Poljakov / Valentina B. Žiromskaja (Hrsg.): Naselenie Rossii v XX veke. Istoričeskie očerki (Die Bevölkerung Russlands im 20. Jahrhundert. Historischer Abriss), T. 2, 1940-1959, Moskau 2001, S. 26.

10 Die Bezeichnung war in sowjetischen Medien bald nach dem deutschen Überfall aufgekommen, doch erst am 20. Mai 1942 wurde sie vom Präsidium des Obersten Sowjets formalisiert. Bis heute heißt der Zweite Weltkrieg in Russland so.

11 Baberowski: Verbrannte Erde (Anm. 7), S. 294-304; Harald Moldenhauer: Die Reorganisation der Roten Armee von der ,Großen Säuberung' bis zum deutschen Angriff auf die UdSSR (1938-1941), in: Militärgeschichtliche Zeitschrift 55, Heft 1, 1996, S. 131-164. 
und Angriffsbefehle zu gewährleisten, hatte Stalin im Juli 1941 den Kommandeuren der Roten Armee politische Kontrolleure in Gestalt der Kriegskommissare an die Seite gestellt und damit ihre Entscheidungsgewalt drastisch eingeschränkt, denn jeder Befehl bedurfte der Gegenzeichnung durch den Kommissar. ${ }^{12}$

Im Oktober 1942 wurden die Offiziere von der Bevormundung durch die Kriegskommissare befreit und erhielten ihre volle Befehlsgewalt zurück. Zur Aufwertung der Offiziere, die mit der Stiftung der drei nach russischen Feldherren benannten Kommandeursorden begonnen hatte, gehörten auch die Wiedereinführung auffälliger Rangabzeichen im Januar 1943, die als Symbol des Zarismus 1917 abgeschafft worden waren, sowie privilegierte Verpflegung. ${ }^{13}$

Dass sich Offiziere mit dem Vorbild berühmter Feldherren der Geschichte motivieren ließen, leuchtet unmittelbar ein. Wie aber mobilisierte das Regime die Millionen von Rotarmisten, von denen das Gros aus den Kolchosen kam - eine breite Schicht unterprivilegierter junger Männer mit rudimentärer Schulbildung? Darüber können sowjetische Kriegsplakate Auskunft geben, die sich an ein breites Publikum, nicht nur an Kommandeure wandten. Die sowjetischen Plakate appellierten vor allem an den Beschützerinstinkt gegenüber Frauen und Kindern, sie erzeugten Hass auf den Feind: „Kämpfer der Roten Armee, rette uns!“, fleht eine bedrohte Mutter. „Kämpfer der Roten Armee! Überlasse deine Liebste nicht der Schande und Entehrung durch die Hitler-Soldaten!“, heißt es unter der Abbildung einer gefesselten jungen Frau. Die Rettung kann nur durch erbitterten Kampf erfolgen: „Räche!“”, „Tod dem faschistischen Scheusal“, lauten die Parolen auf den Plakaten. Eng damit verbunden ist ein moralisch-patriotischer Appell: „Mutter Heimat ruft!“ - eines der stärksten Kriegsplakate überhaupt (Abb. 2, 3 und 4).

Besonders interessant für die Frage nach dem Stellenwert der historischen Figuren für die breite Masse der sowjetischen Soldaten aber ist ein Plakat (Abb. 5), das den Kampf der Rotarmisten im Zweiten Weltkrieg in eine Traditionslinie stellt mit dem mittelalterlichen Fürsten Aleksandr Nevskij (ganz hinten mit dem Schwert), mit Generalissimus Suvorov (in der Mitte, mit dem Säbel) und mit dem Bürgerkriegshelden Čapaev (im Vordergrund, mit dem Maschinengewehr). ${ }^{14}$

12 Hoffmann: Stalins Vernichtungskrieg (Anm. 6), S. 102-104; Baberowski: Verbrannte Erde (Anm. 7), S. 433.

13 Figes: Die Flüsterer (Anm. 9), S. 602-603.

14 Vasilij Ivanovič Čapaev (1887-1919) war im Ersten Weltkrieg als Unteroffizier der Zarenarmee mit den drei unteren Klassen des Georgskreuzes ausgezeichnet worden, bevor er nach der Oktoberrevolution zu den Bolschewiki stieß und im Bürgerkrieg als Kommandeur und Militärkommissar nach etlichen Siegen an der Uralfront gegen die Weißen rasch aufstieg. Er wurde einer der ersten mit dem Rotbannerorden ausgezeichneten Militärführer, starb aber bei einem Gegenstoß der Weißen im September 1919 in seinem 33. Lebensjahr. Das ermöglichte seine Heroisierung wesentlich. Bis heute gibt es in Russland, Weißrussland, in der Ukraine und in Kasachstan Orte, die nach ihm benannt sind beziehungsweise nicht rückbenannt wurden. 


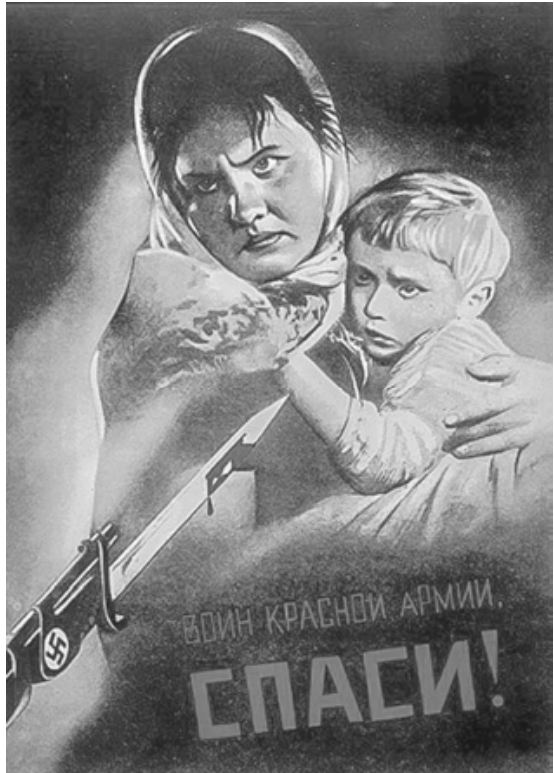

a)

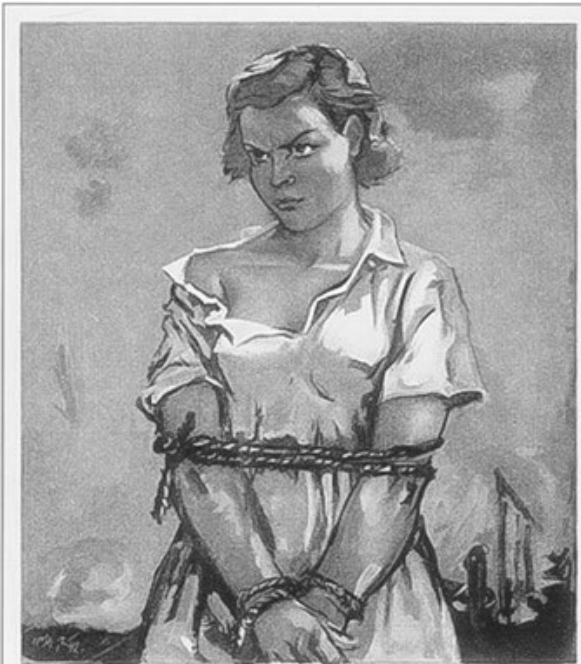

БОЕЦ КРАСНОЙ АРМИИ!

Ты не дашь любимую на позор и бесчестье гитлеровским солдатам.

b)

Abb. 2: a) Plakat „Soldat der Roten Armee, rette uns!“, 1942; b) Plakat „Kämpfer der Roten Armee! Überlasse deine Liebste nicht der Schande und Entehrung durch die Hitler-Soldaten!“, 1942.

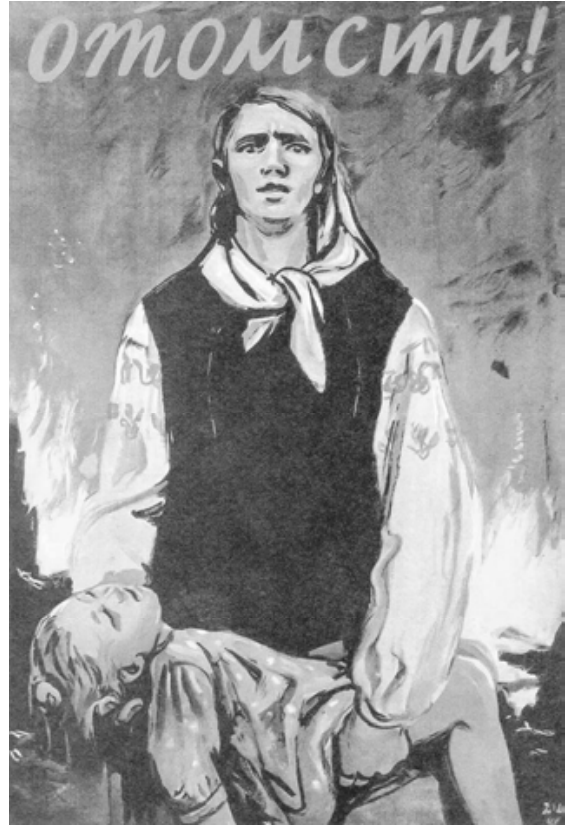

a)

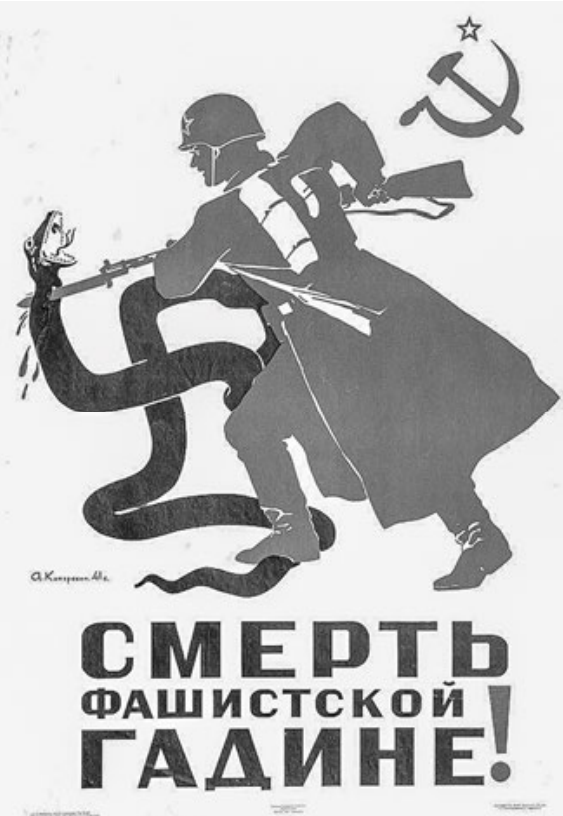

b)

Abb. 3: a) Plakat „Räche!“, 1942; b) Plakat „Tod dem faschistischen Scheusal!“, 1941. 


\section{POАИНА-MAТВ 3OBET!}

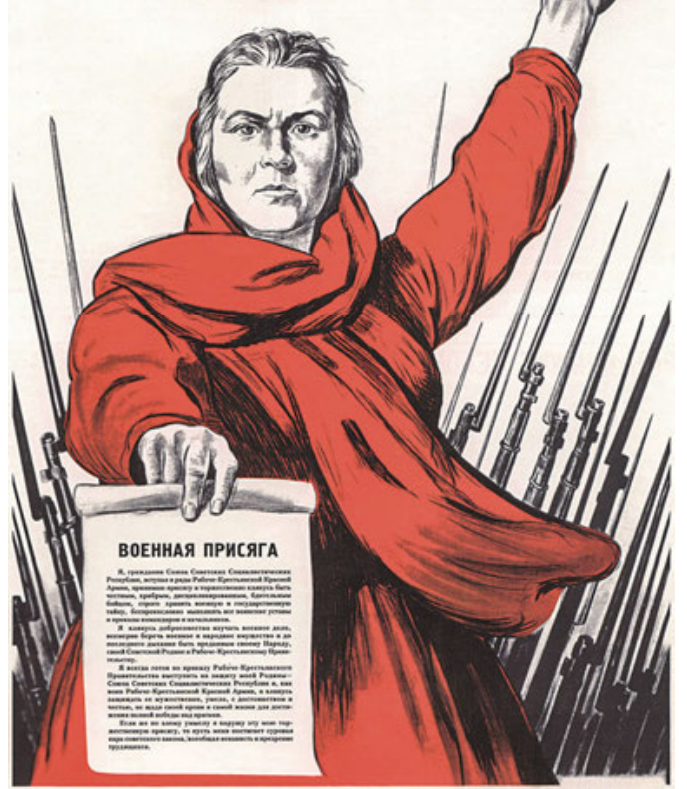

Abb. 4: Plakat „Mutter Heimat ruft!“, 1941.

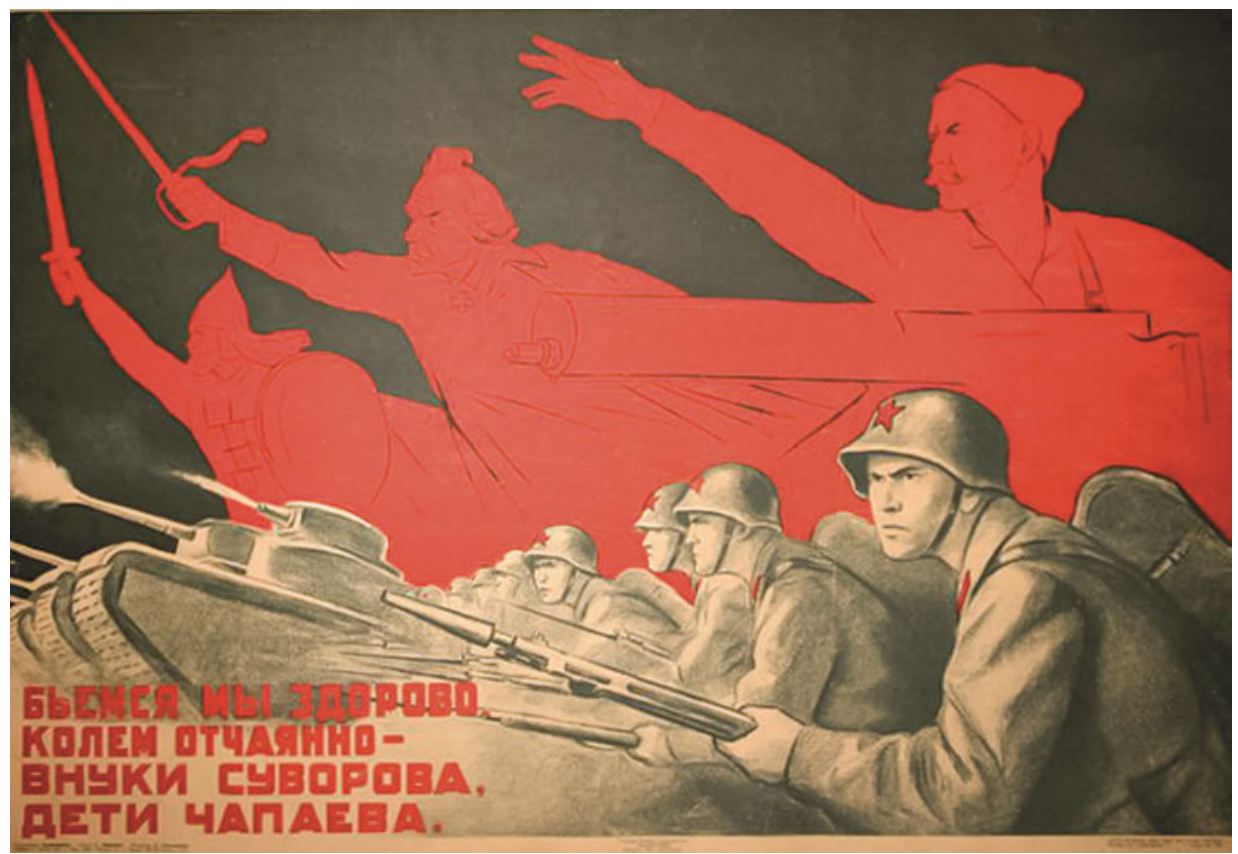

Abb. 5: Plakat „Schlagen wir uns prächtig, stechen wir beherzt zu - die Enkel Suvorovs, die Kinder Čapaevs“, 1941. 
Das Plakat zeigt, dass Suvorov als Vorbild und Identifikationsfigur nicht nur gegenüber den hohen Offizieren, sondern auch gegenüber den einfachen Rotarmisten in Stellung gebracht wurde, von denen etwa 70 Prozent aus dem Dorf beziehungsweise aus den Kolchosen kamen. ${ }^{15}$ Die Rotarmisten werden angesprochen als „Enkel Suvorovs“. Wie aber sollten sie sich als Enkel einer Figur fühlen, die mit der Lebenswirklichkeit von Bauernsoldaten so gar nichts gemein hatte?

Das Plakat selbst bietet keine Informationen über die historischen Vorbilder, setzt also voraus, dass der Betrachter die abgebildeten Personen kennt. Was aber konnte ein Rotarmist, der aus der Kolchose rekrutiert wurde, über Aleksandr Nevskij, Suvorov und Čapaev wissen? Hier kommt ein Medium ins Spiel, das für die Formierung von Geschichtsbildern in der breiten Bevölkerung eine viel größere Rolle spielt als das Buch: der Spielfilm. Im Jahr 1934 war der Bürgerkriegsheld Čapaev in einem Spielfilm popularisiert worden. Dieser Film war einer der größten Erfolge der sowjetischen Filmgeschichte. Wer damals in der Sowjetunion lebte, hatte diesen Film gesehen, viele sogar mehrmals. Das Kriegsplakat von 1942 konnte daher auf das Wiedererkennen setzen und bediente sich desselben Motivs wie das Filmplakat von 1934 (Abb. 6), das 1938 auch auf einer Briefmarke unters Volk gebracht worden war.

Ganz ähnlich verhält es sich mit Suvorov. Beginnend mit dem Jahr 1937 wurde auf Anordnung des Politbüros eine Reihe von Filmen gedreht, die ,großen Männern' der russischen Geschichte gewidmet waren. Diese Filme, die landesweit in den Kinos liefen und die damals so gut wie jeder Sowjetbürger kannte, gehören in den Kontext dessen, was in der Historiographie zur Sowjetunion als die ,patriotische Wende' bezeichnet wird: eine Rückbesinnung auf Patriotismus, Traditionen und ruhmreiche Episoden der russischen Geschichte zum Zwecke der „Mobilisierung der Vergangenheit“. ${ }^{16}$

Führerpersönlichkeiten, denen besondere gestalterische Kraft für die Geschichte Russlands zugeschrieben wurde, kehrten in die Schulbücher zurück und wurden zum Thema von Spielfilmen gemacht: Aleksandr Nevskij, Ivan der Schreckliche,

15 Vgl. Mark Edele: Veterans and the Village: The Impact of Red Army Demobilization on Soviet Urbanization, 1945-1955, in: Russian History. Histoire Russe 36, Heft 2, 2009, S. $159-182$.

16

Zamost'janov: Genij Vojny Suvorov (Anm. 2), S. 499. Zum Sowjetpatriotismus unter Stalin siehe David Brandenberger: National Bolshevism: Stalinist Mass Culture and the Formation of Modern Russian National Identity (Russian Research Center Studies; 93), Cambridge, Mass. 2002; Erwin Oberländer: Sowjetpatriotismus und russischer Nationalismus, in: Andreas Kappeler (Hrsg.): Die Russen. Ihr Nationalbewußtsein in Geschichte und Gegenwart (Nationalitäten- und Regionalprobleme in Osteuropa; 5), Köln 1990, S. 83-90; Ewa M. Thompson: Nationalist Propaganda in the Soviet Russian Press, 1939-1941, in: Slavic Review 50, Heft 2, 1991, S. 385-399; Gennadij A. Bordjugow: Die Kosten des bolschewistischen Sprechens: Die Intelligenzija und der Sowjetpatriotismus, in: Dietrich Beyrau (Hrsg.): Im Dschungel der Macht. Intellektuelle Professionen unter Stalin und Hitler, Göttingen 2000, S. 300-318; Serhy Yekelchyk: Stalinist Patriotism as Imperial Discourse: Reconciling the Ukrainian and Russian ,Heroic Pasts', 1939-45, in: Kritika: Explorations in Russian and Eurasian History 3, 2002, Heft 1, S. 51-80. 


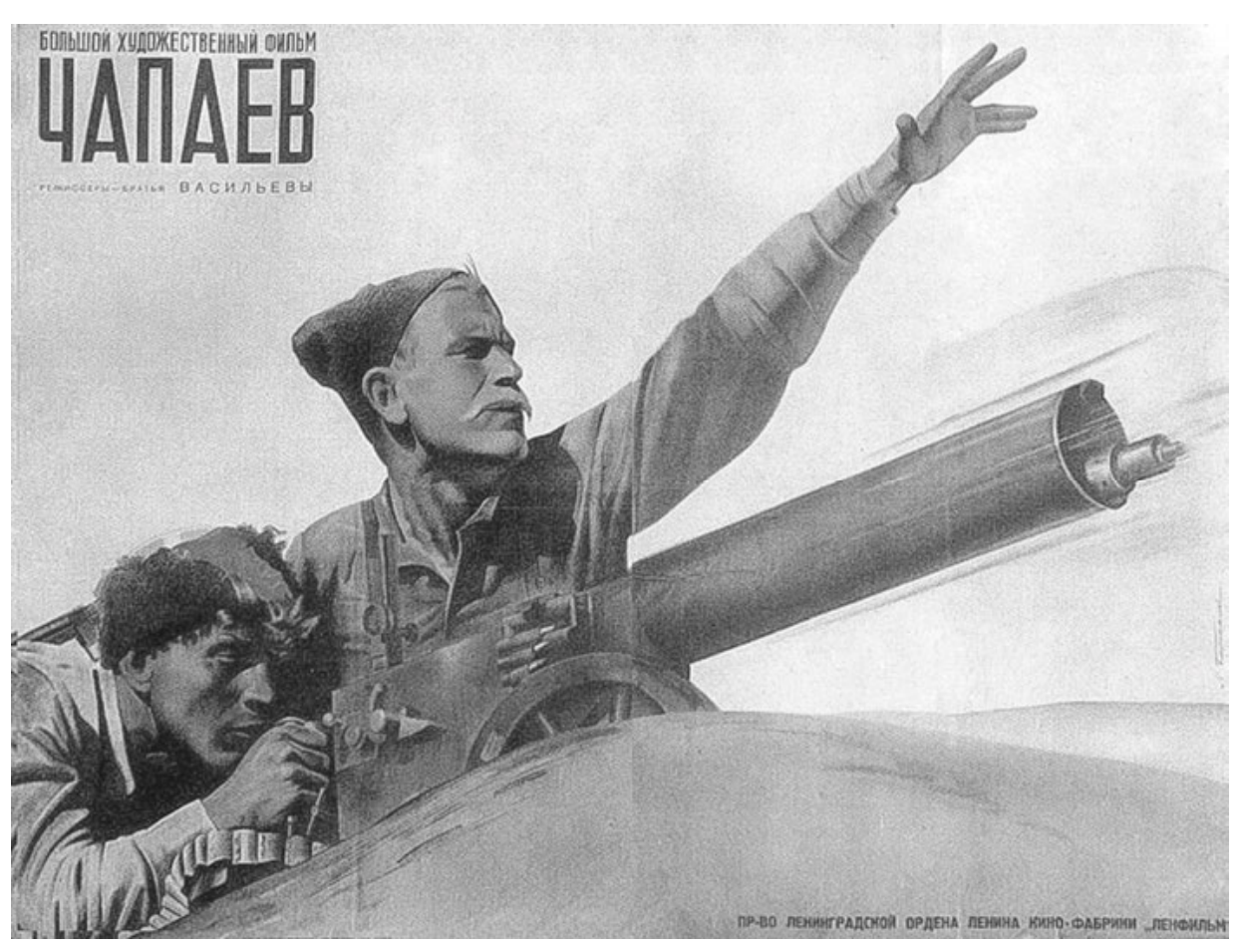

Abb. 6: Filmplakat „Čapaev“, 1935.

Minin und Požarskij, Peter der Große - und eben Suvorov (Abb. 7). Auch hier sieht man ganz deutlich, wie das Kriegsplakat von 1942 den Film aufgreift, bis hin zur charakteristischen Haartolle und Säbelquaste. Bis heute ist der Film populär. Wer in Russland den Namen Suvorov hört, denkt häufig zu allererst an diesen Film. Noch stärker ist die Bezugnahme auf den Film bei Aleksandr Nevskij: Hier bedient sich sogar der Orden des Films: Auf dem Orden ist nämlich gar nicht Aleksandr Nevskij abgebildet, sondern der Schauspieler Nikolaj Čerkassov (Abb. 8), der ihn 1938 im Film verkörperte, da es keine zeitgenössische Abbildung des Fürsten gibt und sich Ikonen und andere spätere idealisierende bildliche Darstellungen nicht für einen Militärorden eigneten. Zu jeder historischen Persönlichkeit, nach der im Zweiten Weltkrieg ein sowjetischer Militärorden benannt wurde, wurde zwischen 1940 und 1953 auch ein Spielfilm gedreht: „Aleksandr Nevskij“ (1938), „Suvorov“ (1940), „Kutuzov“ (1943), „Bogdan Chmel’nickij“ (1941), „Admiral Nachimov“ (1946), „Admiral Ušakov“ (1953). ${ }^{17}$

17 Evgenij Dobrenko, Ordena, oni že ljudi, ili istorija s biografiej (Orden, das sind Menschen, oder eine Geschichte mit einer Biographie), in: Kinovedčeskie zapiski 74, 2005, S. 18-56, http://www.kinozapiski.ru/ru/article/sendvalues/443/, 17. April 2015. Für die Rezeption der Figur Aleksandr Nevskijs und seine mehrfache Adaptierung an die Bedürfnisse der Zeitgenossen über mehrere Jahrhunderte hinweg siehe Frithjof Benjamin Schenk: Alexander Nevskij. Heiliger - Fürst - Nationalheld. Eine Erinnerungsfigur im russischen kulturel- 


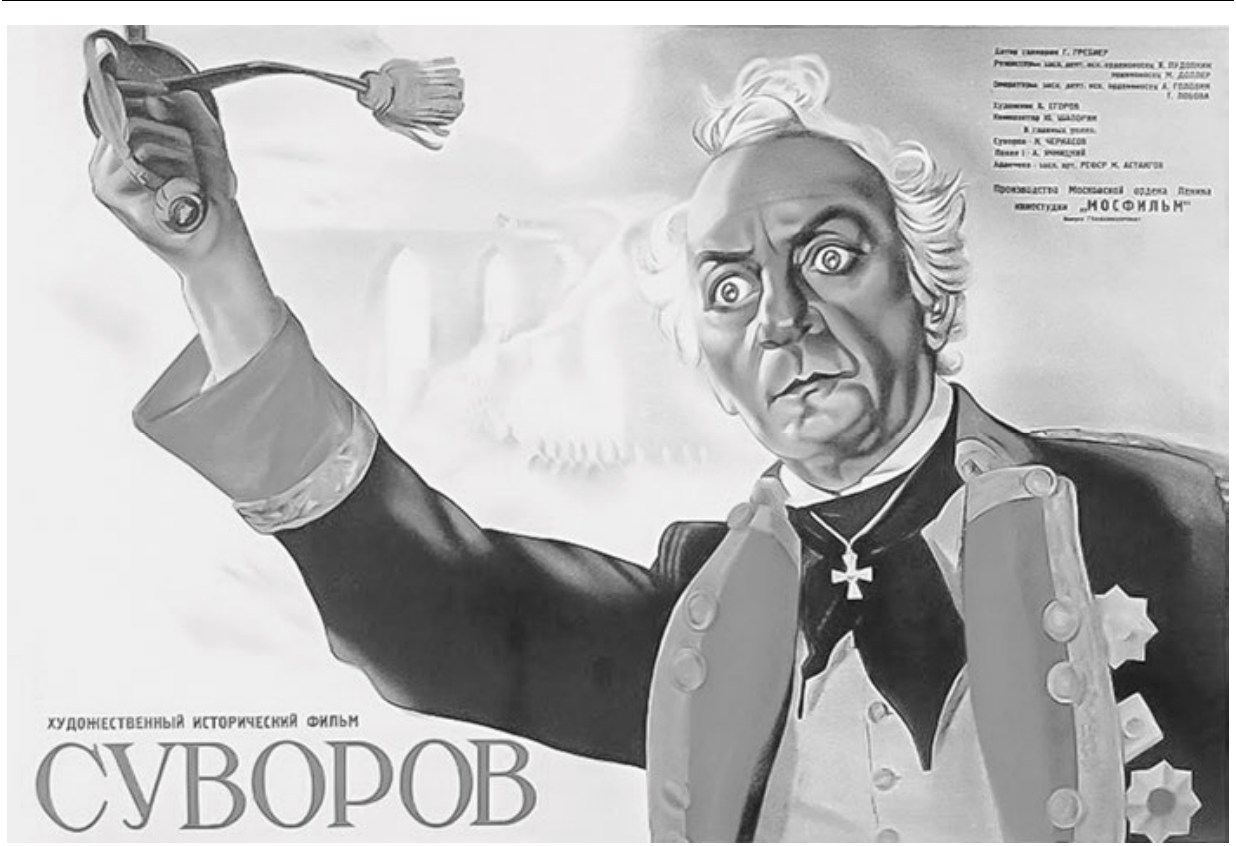

Abb. 7: Filmplakat „Suvorov“, 1941.

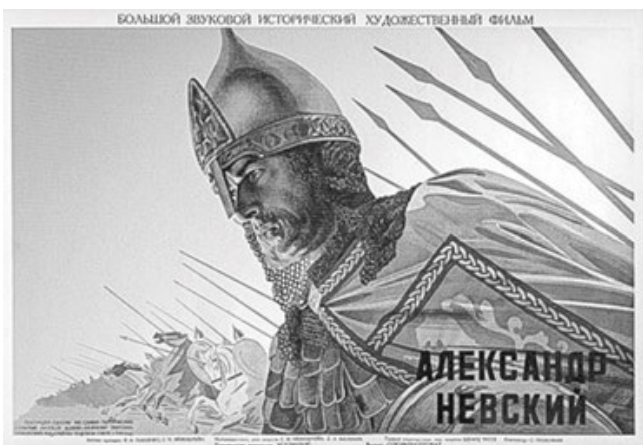

a)

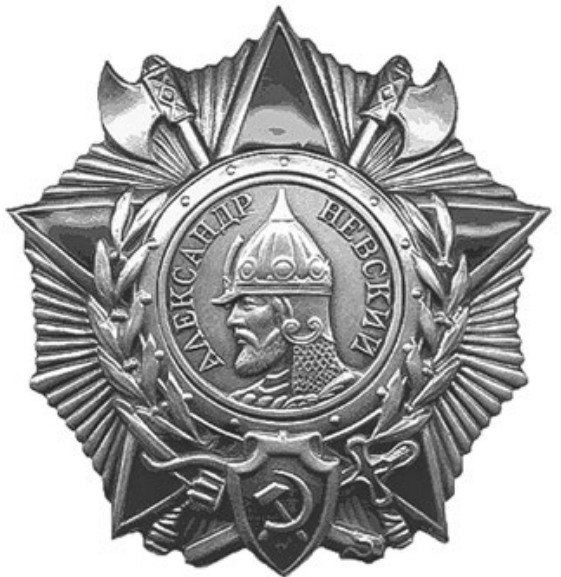

b)

Abb. 8: a) Der Schauspieler Nikolaj Čerkassov als „Aleksandr Nevskij“, 1938; b) Der AleksandrNevskij-Orden, 1942.

len Gedächtnis 1263-2000 (Beiträge zur Geschichte Osteuropas; 36), Köln [u.a.] 2004; speziell zur Aufwertung Nevskijs im Kontext des Sowjetpatriotismus: Ders.: „Ein so guter Fürst darf nicht sterben!“. Die Rehabilitierung und Verehrung Aleksandr Nevskijs in der UdSSR in den Jahren 1937/38, in: Klaus Heller / Jan Plamper (Hrsg.): Personality Cults in Stalinism / Personenkulte im Stalinismus, Göttingen 2004, S. 391-413. 
Die Eingangssequenz des Filmes „Suvorov“ ist ein Musterbeispiel für die mediale Adaptierung des historischen Feldherrn für die Bedürfnisse der Sowjetunion im Zweiten Weltkrieg. Keine Bildeinstellung ist zufällig, kein Satz ist belanglos, sondern hier werden dem Publikum wichtige Botschaften auf emotionale Weise vermittelt, die sich unterschwellig im Bewusstsein einnisten. Der Film über Suvorov wurde 1940 gedreht, also in der Zeit zwischen dem Hitler-Stalin-Pakt und dem Beginn des deutsch-sowjetischen Krieges. Vor dem Hintergrund dessen, dass Hitler und Stalin gerade Polen unter sich aufgeteilt hatten, verwundert es nicht, dass der Film mit einer Szene beginnt, die unmittelbar nach dem Sieg der Russen über die aufständischen Polen 1794 spielt. Man sieht das russische Heerlager vor den Toren Warschaus nach der Schlacht. Suvorov wird von seinen Soldaten auf den Schultern getragen, sie jubeln ihm zu. Es wird aber schnell klar, dass gar nicht so sehr Suvorov als Held inszeniert wird, obwohl er die eindeutige und titelgebende Hauptperson des Films ist. Er fungiert vielmehr als ,Heldenmacher'. Es findet eine Übertragung von Heldentum statt: vom Feldherrn, dessen Heldentum als gegeben vorausgesetzt wird, auf die Soldaten. Nicht Suvorov wird in diesem Film als Held bezeichnet, sondern er bezeichnet seine Soldaten als Helden und zwar ständig. Das beginnt schon mit den ersten Worten, die er spricht: „Wunder-Recken! Helden!“, ruft er den Soldaten zu. ${ }^{18}$ Das setzt sich den gesamten Film hindurch fort.

Die erste Person, die Suvorov persönlich anspricht, ist ein einfacher Bauernsoldat, also eine Figur, in der sich ein Rotarmist wiedererkennen kann. Und dieser Bauernsoldat erfährt eine persönliche Wertschätzung durch den großen Feldherrn: „Du bist ein Held!“, sagt Suvorov zu ihm, „Adler sollst du heißen, nicht Meise!“19 Und dem zuständigen Unterführer dankt er „für den neuen Helden“. Der Bauernsoldat und sein Offizier blühen geradezu auf vor Stolz und Dankbarkeit. Der Blick des Soldaten, den er Suvorov nachwirft, stellt eine affektive Verbindung her zwischen dem Ruhm des Feldherrn und dem Heldentum des einfachen Soldaten.

Die Wertschätzung für die Soldaten wird im Film mehrmals thematisiert. Das Lob für die Regimentskommandeure ist als Lob für die Soldaten formuliert, während die Fehler nicht den Soldaten, sondern den Offizieren angelastet werden: „Deine Phanagoräer - ausgezeichnet!“, ruft Suvorov dem Kommandeur des Phanagoräischen Regiments zu. ${ }^{20}$ Den Kommandeur des Azover Regiments enthebt er auf der Stelle des Kommandos, weil er seine Männer sinnlos in den Tod geschickt hat. ${ }^{21}$ In einer späteren Szene gerät Suvorov mit dem Zaren in Streit, weil dieser ihm das Kommando über „unsere vollkommene Militärmaschine“ über-

18 Suvorov. Studio Mosfil'm, Moskau 1940, 00:02:09-00:02:30.

19 Ebd., 00:03:22-00:03:30. Der Soldat hatte zuvor seinen wirklichen Namen genannt - „Sinica" (Meise).

20 Ebd., 00:04:10-00:04:13.

21 Ebd., 00:04:40-00:05:15. 
gibt und Suvorov entgegnet, er „bringe es nicht fertig, eine Maschine zu befehligen“: „Ich befehlige Menschen, Euer Majestät!“, sagt er ernst. ${ }^{22}$

Systematisch wird also in diesem Film dem anonymen Sterben im technisierten Massenkrieg und der Menschenverachtung der Materialschlacht ein Bild gegenübergestellt, in dem der Krieg zur persönlichen Bewährungsprobe von Soldaten und Offizieren wird, in dem individuelles Heldentum möglich ist. Die Schrecken des Krieges kommen in diesem Film nicht vor, sondern der Krieg besteht aus einer Aneinanderreihung von Siegen, die durch die heldenhafte Selbstüberwindung der Soldaten und die Führungsqualitäten des Feldherrn errungen werden.

Die Soldaten sind die eigentlichen Helden, aber sie sind es nur dank Suvorov. Ihr Heldentum ist kein selbstständiges, sondern bedarf des Führers. Die Soldaten werden infantilisiert, sie sind auf Anleitung angewiesen. Suvorov bildet mit ihnen zusammen eine große Familie. Er ist der ,Vater, die Soldaten sind die ,Kinder", die ihn lieben. „Meine Küken“ („moi ptency“) nennt er sie in der ersten Szene. ${ }^{23}$ Diese zunächst irritierende Formulierung erschließt sich nur im kulturellen Kontext der Zeitgenossen. Sie stellt über Aleksandr Puškin, der anlässlich seines hundertsten Todestages 1937 eine enorme Aufwertung und Popularisierung als russischer Nationaldichter erfahren hatte, ${ }^{24}$ eine Verbindung zu Peter dem Großen her. Puškin bezeichnete 1829 in seinem Gedicht „Poltava“ einige der militärischen Weggefährten Peters als die „Küken aus dem Nest Peters des Großen“ („ptency gnezda Petra Velikogo“). Die Wendung benutzte Puškin auch in seinem Roman „Der Mohr Peters des Großen“ („Arap Petra Velikogo“).

Angesichts des Umstandes, dass 1936/37 im Zusammenhang mit dem PuškinJubiläum mehr als 20 Millionen Exemplare seiner Werke gedruckt worden waren und das Lesen klassischer Literatur in der Sowjetunion der 1930er Jahre dank der fortgeschrittenen Alphabetisierungs- und Bildungsoffensive zu einer Angelegenheit der breiten Volksmassen geworden war, ${ }^{25}$ kann man davon ausgehen, dass ein beträchtlicher Teil des Publikums diesen Bezug auf Puškin und Peter den Großen verstand. Dass die Formulierung keine Nebensächlichkeit war, beweist ein Interview mit dem Drehbuchautor Georgij Grebner vom Februar 1941. Im Zusammenhang mit der Ankündigung, das Drehbuch für einen Fortsetzungsfilm zu schreiben, sprach er von den „Suvorov-Küken“ und legte zugleich offen, wie die historischen Bezüge zu verstehen seien:

„Im Film ,Der Sturm von Izmail‘ entfalten wir wieder einige großartige Seiten aus der heroischen Vergangenheit der unbesiegbaren russischen Armee. Wir erzählen über den Ruhm und den Heroismus der ,Suvorov-Küken“ - der Vorfahren unserer glänzenden

22 Ebd., 00:51:25-00:51:28.

23 Ebd., 00:02:17-00:02:18.

24 Zum Puškin-Jubiläum siehe Karl Schlögel: Terror und Traum. Moskau 1937, München 2008, S. 198-217.

25 Ebd., S. 215. 
Rotarmisten-Kämpfer, wir erzählen über die feste Kampffreundschaft zweier genialer Feldherren - Aleksandr Suvorovs und seines liebsten Schülers Michail Kutuzov.“26

Damit stellte Grebner gleich mehrere Verbindungslinien zwischen der Vergangenheit und der Gegenwart her: Die Siege der russischen Armee im 18. und frühen 19. Jahrhundert wurden ebenso mit der Gegenwart verknüpft wie der Heroismus der Soldaten und die Kontinuität genialer Führer von Peter dem Großen über Suvorov und Kutuzov bis zu Stalin. Die Formulierung „sein liebster Schüler“ war dem sowjetischen Publikum aus der damaligen Propaganda geläufig als eine der üblichen Charakterisierungen des Verhältnisses zwischen Stalin und Lenin.

Der Bezug zu Stalin kulminiert in der dramatischen Schlusssequenz des Filmes, die in den Schweizer Alpen spielt, vor und während der Schlacht an der Teufelsbrücke über die Schöllenenschlucht beim Gotthardpass. ${ }^{27}$ Der Film zeigt, wie es Suvorov gelingt, durch einen emotional-persönlichen Appell die völlig erschöpften Soldaten, die nicht mehr weiterkämpfen wollen, mitzureißen und die Stimmung in der Truppe zu wenden: „Seid ihr mir keine Kinder mehr?“, fragt er sie, „bin ich nicht euer Vater?" ${ }^{\text {"28 }}$ Die Soldaten lassen sich noch einmal zum entscheidenden Kampf motivieren und danken ihrem Führer: „Blind sind wir wohl geworden, sa-

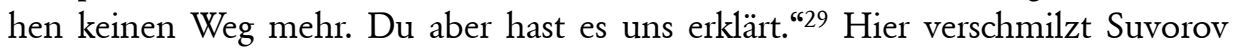
quasi mit Stalin, dem weisen Führer. Er führt seine Soldaten in den Sieg, der eine helle Zukunft verheißt: „Wir fallen den Franzosen in den Rücken und erreichen dann das grüne Tal. Da gibt es so viel Brot und Sonne, wie man sich wünscht." ${ }^{\text {"30 }}$

Schon die Eingangssequenz enthielt überdeutlich die Botschaft, dass der einfache Soldat als Individuum gewürdigt wird und durch Leistung aufsteigen kann. Major Tjurin, dem Suvorov das Kommando über das Azover Regiment überträgt, war einmal ein einfacher Soldat gewesen, ein Umstand, der nicht beiläufig erwähnt, sondern plakativ ausgesprochen wird. „Denn ein Soldat geht dem Vaterland über alles!“31 - In diesem Satz kulminiert die Eingangssequenz des Films. Die Rotarmisten von 1940 sollen sich wiedererkennen in diesem Tjurin, der es bis zum Oberst gebracht hat.

26 Večernjaja Moskva vom 5. Februar 1941, Zeitungsausschnitt im Russischen Literatur- und Kunstarchiv Moskau (RGALI) f. 1966, op. 1, d. 256, Bl. 80a.

27 An der Teufelsbrücke schlugen die russischen Truppen unter Suvorov im Zweiten Koalitionskrieg am 25. September 1799 französische Verbände unter General Claude-Jacques Lecourbe. 1899 wurde dort auf einem Grundstück, das bis heute dem russischen Staat gehört, zur Erinnerung ein russisches Suvorov-Denkmal errichtet. Bei seinem Staatsbesuch in der Schweiz besuchte der Präsident der Russischen Föderation Dmitrij Medvedev am 22. September 2009 das Denkmal.

Suvorov (Anm. 18), 01:37:20-01:37:25. Die Szene samt den Worten Suvorovs ist einer Suvorov-Anekdote entnommen, die eine Episode vor dem Übergang über den St. Gotthard beschreibt, als sich die Soldaten geweigert hatten weiterzumarschieren, geschildert in Lopatin: Suvorov (Anm. 2), S. 381, mit Bezug auf die Verwendung im Film.

30 Ebd., 01:36:40-01:36:46.

31 Ebd., 00:05:55-00:06:06. 
Dabei kommt noch eine weitere Ebene hinzu, die in anderen Episoden des Films deutlicher wird als in der gezeigten: Suvorov bleibt stets volksverbunden und kommt als bauernschlaues Schlitzohr daher, mit durchaus komödiantischen Zügen. In einer Rezension des Films vom Januar 1941 war sogar vom „großen VolksFeldherren“ („velikij narodnyj polkovodec") die Rede. ${ }^{32}$ Diese Figuration erinnert an diejenige des Bürgerkriegshelden Čapaev im gleichnamigen Film aus dem Jahr 1934. Der Bürgerkriegsheld Čapaev verschmilzt mit dem Feldherrnhelden Suvorov, so wie die beiden auch auf dem Kriegsplakat (Abb. 5) miteinander verschmelzen.

Diese Überlagerung, verbunden mit dem Transfer des Heldentums vom Feldherrn auf die einfachen Soldaten, erleichtert die Identifikation der Zuschauer mit dem, was ihnen an vorbildhaftem Verhalten gezeigt wird. Der Massenkrieg mit seinem anonymen Sterben wird ausgeblendet und durch ein traditionell-heroisches Bild ersetzt. Der Vorstellung vom einfachen Soldaten als Teil einer anonymen Masse und als namenloses Kanonenfutter wird die Suggestion vom individuellen Helden entgegengestellt, der einen Namen hat - Suvorov fragt nicht umsonst den ersten Soldaten, den er anspricht, gleich zu Beginn nach seinem Namen. Angeleitet von einem verantwortungsvollen Führer kann der Soldat übermenschliche Leistungen erbringen und erfährt dafür persönliche Wertschätzung. Mit der Realität des Kämpfens und Sterbens der Rotarmisten im Zweiten Weltkrieg hatte das freilich wenig gemein. Keine andere Armee opferte ihre Soldaten so rücksichtslos und sinnlos wie die sowjetische - aber um diese Realität geht es hier nicht, sondern um die Suggestion. ${ }^{33}$

Der Film „Suvorov“ wurde mit großem medialem und organisatorischem Aufwand unters Volk gebracht und in seiner heroisierenden Absicht durch begleitende Veranstaltungen und Publikationen verstärkt. Schon im Dezember 1937 hatte die „Kino-Zeitung“ Auszüge aus dem Drehbuch publiziert und die Regierungszeitung „Izvestija“ den Film angekündigt. ${ }^{34}$ Die Premiere des Films im Januar 1941 hatte eine Flut von Zeitungsartikeln zur Folge. In einem großen Moskauer Kino wurde eine Begleitausstellung gezeigt mit Originalporträts, Briefen, Dokumenten und einer Bücherschau. Das Kino veranstaltete Treffen der $\mathrm{Zu}$ schauer mit den Schauspielern, dem Regisseur und dem Drehbuchautor. Militärfachleute und Mitarbeiter des Staatlichen Historischen Museums führten durch

32 Sovetskaja Ukraina vom 29. Januar 1941, RGALI f. 2014, op. 1, d. 170, Bl. 67.

33 Den Alltag der Rotarmisten beschreibt eindrücklich Merridale, Iwans Krieg (Anm. 9). Zu der vor einigen Jahren wieder aufgeflammten Diskussion um die Verluste der Roten Armee vgl. I. I. Ivlev: „... a v otvet tišina - on včera ne vernulsja iz boja!“ (,,... und als Antwort Schweigen - er ist gestern nicht aus dem Kampf zurückgekehrt!“), in: Igor’ V. Pychalov (Hrsg.): „Umylis’ krov’ju“? Lož i pravda o poterjach v Velikoj Otečestvennoj vojne („Haben sie sich mit Blut gewaschen?"Lüge und Wahrheit über die Verluste im Großen Vaterländischen Krieg), Moskau 2012, S. 479-506.

34 Kino-gazeta vom 18. Dezember 1937, Izvestija vom 21.Dezember 1937, RGALI f. 1966, op. 1, d. 256, Bl. 62-63. 
die Ausstellung. ${ }^{35}$ Nach nur sechs Tagen hatten in 17 Moskauer Kinos bereits 425.000 Menschen den Film gesehen. ${ }^{36}$

Betriebsbelegschaften gingen geschlossen in die Vorstellungen. „Die Genossen äußern sich begeistert über den Film, der bei den Zuschauern patriotische Gefühle weckt und die ruhmreiche Vergangenheit des heldenhaften russischen Volkes wieder auferstehen lässt“, schrieb eine Lokalzeitung aus der Stadt Kaluga über den kollektiven Kinobesuch der Arbeiter eines großen Werkes. Der Film zeige Suvorov, so der Kommentar, aber er zeige gleichzeitig die "unvergesslichen Helden unserer Vergangenheit, die russischen Soldaten“. „Der Film ,Suvorov“ ist ein Film über den genialen Feldherren der russischen Armee, ein Film über das heldenhafte russische Volk, ein Film über einen Helden - den russischen Soldaten. " ${ }^{37}$ Eine andere Zeitung zitierte einen Unterleutnant der Roten Armee, der die Verbundenheit Suvorovs mit seinen Soldaten hervorhob: „Den Feldherren Suvorov liebten die russischen Krieger und sie gingen für ihn in den Kampf, ihr Leben nicht achtend. Dieser Film erzieht unser Volk im Geiste der Ergebenheit der Heimat. Der Film ,Suvorov` ist das beste Mittel für die Kämpfer der Roten Armee. ${ }^{\text {"38 }}$

Während im Film und in seiner medialen Begleitung die patriotische Botschaft, die Heroisierung der einfachen Soldaten und das väterliche Verhältnis Suvorovs zu seinen Männern im Vordergrund standen, hatte Stalin noch während der Dreharbeiten korrigierend eingegriffen und das Drehbuch kritisiert. Ihm war die Figuration des Helden zu einseitig. Wie kurze Zeit später im Krieg gegen die Wehrmacht wollte er die „weichen“ Elemente durch Führungsstärke, militärisches Können und Disziplinierung ergänzt wissen: „Das Drehbuch von ,Suvorov“ leidet unter Mängeln“, schrieb er im Juni 1940 an den Vorsitzenden des Filmkomitees beim Rat der Volkskommissare, Ivan Bol'šakov:

„Man muss aufhören, Suvorov als lieben Papa darzustellen. Und auch die Sache mit dem ganzen ,Kikeriki'-Schreien und dem ,Russisch'-,Russisch'-Gerede. ${ }^{39}$ Darin liegt nicht das Geheimnis der Siege Suvorovs.

Im Drehbuch werden die Besonderheiten der Kriegspolitik und der Taktik Suvorovs nicht aufgedeckt: 1) die richtige Einschätzung der Schwächen des Gegners und das Vermögen, diese vollständig auszunutzen, 2) ein gut durchdachter und kühner Angriff, koordiniert mit einem Umgehungsmanöver, um dem Gegner in den Rücken zu stoßen, 3) das Vermögen, erfahrene und tapfere Kommandeure auszuwählen und sie auf das Objekt des Angriffs auszurichten, 4) das Vermögen, Personen, die sich ausgezeichnet haben,

35 Večernjaja Moskva vom 14.1 Januar 1941, RGALI f. 2014, op. 1, d. 170, B1. 30.

36 Pravda vom 28. Januar 1941, ebd., B1. 66.

37 Kommuna (Kaluga) vom 24. Februar 1941, ebd., B1. 213.

38 Kino vom 24. Januar 1941, ebd., B1. 50.

39 Offensichtlich hatte das ursprüngliche Drehbuch noch stärkere komödiantische und russisch-nationale Züge. Dass die massive Kritik Stalins ignoriert worden wäre, ist unter den damaligen Bedingungen schwer vorstellbar. Die kaum adäquat zu übersetzende Stelle lautet im Original: „Pora perestat' izobražat' Suvorova, kak dobren'kogo papašu, to i delo vykrikivajuščego ,ku-ku-re-ku' i prigovarivajuščego ,russkij', ,russkij].“ 
schnell auf hohe Posten zu befördern ohne Rücksicht auf die Ernennungsregeln, das offizielle Dienstalter und die Herkunft, 5) das Vermögen, in der Armee eine harte und wahrhaft eiserne Disziplin aufrechtzuerhalten.

Wenn man das Drehbuch liest, könnte man glauben, Suvorov hätte die Disziplin in der Armee locker genommen und er wäre nicht aufgrund seiner Kriegspolitik und Taktik aufgestiegen, sondern wegen seiner Güte gegenüber den Soldaten und waghalsiger, listiger Aktionen gegen den Feind, die in Abenteurertum ausarteten. Das ist natürlich ein Missverständnis, um nicht mehr zu sagen. “40

\section{Ausblick: Die Aktualisierung Suvorovs in Putins Russland}

In Putins Russland erlebt Suvorov zur Zeit einen neuen Höhepunkt seiner Heroisierung. Davon zeugen mindestens ein Film, mehrere Biographien, Ausstellungen und eine auffallende Präsenz im Internet. Suvorov steht heute ganz oben in der Hierarchie der Helden Russlands. Die Bedeutung Suvorovs für das heutige Russland veranschaulicht schon allein der Umstand, dass es auf der offiziellen Internetpräsenz des Präsidenten der Russischen Föderation 55 Seiten gibt, auf denen von Suvorov die Rede ist. ${ }^{41}$

Suvorov dient in Russland heute geradezu als Maßstab für Heldentum. Am 9. Dezember 2014, dem ,Tag der Helden des Vaterlandes` - diesen Gedenktag gibt es in Russland seit 2007 - wurde in Moskau ein Reiterstandbild für General Michail Skobelev enthüllt, der im 19. Jahrhundert bei der Eroberung Turkestans und auf dem Balkan eine große Rolle gespielt hatte. In seiner Ansprache hob der Leiter der Präsidialverwaltung hervor, die Zeitgenossen Skobelevs hätten ihn als einen Helden bezeichnet, den man mit Suvorov vergleichen könne. ${ }^{42}$

2010 wurde auch der Suvorov-Orden aktualisiert. Er war zwar schon 1992 aus der Sowjetunion übernommen worden, erhielt aber erst 2010 ein neues Statut. Das Medaillon mit dem Reliefporträt blieb unverändert, den Strahlenkranz hat man so zurechtgeschnitten, dass er nicht mehr wie ein Sowjetstern aussieht, neu hinzugefügt wurde ein klassisches Ordenskreuz. Damit sieht der Orden heute aus wie einer aus dem zarischen Russland, hält aber auch die Kontinuität mit dem Orden von 1942 aufrecht (Abb. 9). ${ }^{43}$

Die neue Hochkonjunktur Suvorovs gehört in den Kontext der neoimperialen Ambitionen Russlands seit der Jahrtausendwende. Russland tritt unter Putin nach der Krise der 1990er Jahre wieder selbstbewusst auf, betreibt Machtpolitik und strebt danach, die untergegangene Sowjetunion durch eine eurasische Einflusszone zu ersetzen. „Immer dann, wenn Russland Suvorov vergaß, erlitt es vernichtende

40 Stalin an Bol'šakov, 9. Juni 1940, in: Russisches Staatsarchiv der Sozial-Politischen Geschichte (RGASPI) f. 558, op. 11, d. 159, Bl. 3. Im Faksimile online publiziert unter http://www.liveinternet.ru/users/1298624/post242350734/, 17. April 2015.

41 http://www.kremlin.ru/search?query=Суворов, 17. April 2015.

42 Večernjaja Moskva vom 10. Dezember 2014.

43 https://ru.wikipedia.org/wiki/Орден_Суворова_(Россия), 17. April 2015. 


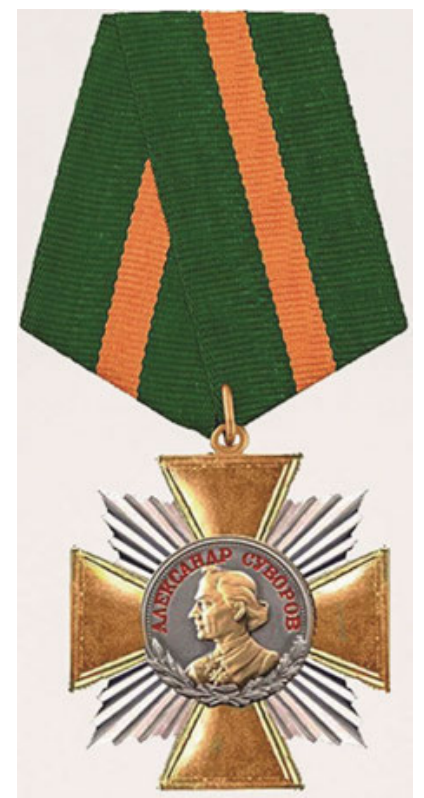

Abb. 9: Suvorov-Orden, 2010.

Niederlagen. Sobald es sich an ihn erinnerte, errang es große Siege." So lautet ein wiederkehrender Satz in neueren russischen Publikationen und Dokumentationen. ${ }^{44}$

Es ist kein Zufall, dass ausgerechnet im russisch-ukrainischen Konflikt 2014 Suvorov aufs Neue in Stellung gebracht wurde. Schon seit einigen Jahren beklagten russische Stimmen, dass die unabhängige Ukraine die vormals gemeinsamen imperialen Helden des Russischen Reiches und der Sowjetunion nicht mehr in Ehren halte. In einem Dokumentarfilm über Suvorov aus dem Jahr 2007 wird kritisiert, dass der Name Suvorovs aus den ukrainischen Schulbüchern getilgt worden sei. ${ }^{45}$ Der Film wurde 2014 auf mehreren russischen Internetseiten verlinkt und der Bezug zur Ukraine noch verstärkt. Die junge Generation in der Ukraine wisse nicht einmal mehr, wer Suvorov war. Und sie kenne daher auch nicht die wirkliche Geschichte von ,Neurussland'. Die Abkehr der Ukraine von Russland sei eine Folge dieser Ignoranz. ${ }^{46}$ Auf anderen Internetseiten wird Igor Gir-

44 Vgl. zum Beispiel Zamostjanov, Genij vojny Suvorov (Anm. 2), S. 10; vgl. den 2007 im russischen staatlichen Fernsehkanal „Rossija“ ausgestrahlten Dokumentarfilm „Velikij polkovodec Suvorov“ („Der große Feldherr Suvorov“), https://www.youtube.com/watch?v= pknZBbJyfE4; siehe auch http://www.km.ru/glavnoe/2007/07/10/rostov-na-donu/presskulbit mit Bezug auf den Film, 17. April 2015.

45 Velikij polkovodec Suvorov (Der große Feldherr Suvorov), https://www.youtube.com/ watch?v=pknZBbJyfE4, 17. April 2015.

46 http://nnils.livejournal.com/2120204.html, 17. April 2015. „Neurussland“ war in der zweiten Hälfte des 18. Jahrhunderts und im 19. Jahrhundert die offizielle Bezeichnung derjenigen Territorien nördlich des Schwarzen und des Azovschen Meeres, die Russland unter Katharina II. eroberte und in der Folge kolonisierte. Der Terminus wird gegenwärtig von rus- 
kin, alias Igor Strelkov, ein russischer Offizier, der in der selbsternannten ,Volksrepublik Doneck ${ }^{\varsigma}$ die militärischen Kräfte der Separatisten organisierte, mit Suvorov in Beziehung gesetzt: „Ist Igor Strelkov ein Nachfahre von Generalissimus Suvorov?" heißt es in der Werbung zu einer Biographie, in der Strelkov als Held verherrlicht wird, der gegen die, amerikanisch-ukrainischen Faschistenhorden und für eine Wiedergeburt Russlands kämpfe: „ritterlich, tapfer und gerecht“, eine Verkörperung der Ehre und des Gewissens von Russland. ${ }^{47}$ Zwei nebeneinander gestellte Bilder sollen suggerieren, dass zwischen Strelkov und einem Enkel Suvorovs eine frappierende Ähnlichkeit bestehe. ${ }^{48}$ Strelkov selbst titulierte sich als "Generalissimus" und wurde in russischen Medien gefeiert als der Held, der in die Fußstapfen Suvorovs trete und für die Freiheit Neurusslands kämpfe. ${ }^{49}$ In einer Variation wiederholt sich hier das Motiv der Übertragung des Heroischen von einem etablierten Helden auf einen neuen. Suvorov als ,Heldenmacher funktioniert hier sogar über die Konstruktion einer fiktiven Abstammungslinie. Der Suvorov-Film von 1940 wurde im Laufe des Jahres 2014 mehrmals im russischen Fernsehen ausgestrahlt und erfreut sich großer Popularität.

Der neu aufgelegte Suvorov-Orden - und damit schließt sich der Kreis - wurde am 18. August 2014 per Dekret von Präsident Putin der 76. Garde-LandungsSturmdivision verliehen, und zwar für „Mut und Heldentum bei der erfolgreichen Ausführung von Kampfaufträgen" .50 Verteidigungsminister Šojgu bezog das in seiner Ansprache auf den Einsatz der Division bei der ,Rückholung' der Krim im März 2014. ${ }^{51}$ Auf russischen Internetseiten findet sich allerdings eine brisantere Begründung: Die 76. Sturmdivision hatte in den Wochen vor der Ordensverleihung viele Gefallene zu beklagen, wofür es nur eine Erklärung gibt, nämlich dass Teile dieser Division in der Ostukraine kämpfen. Offiziell fand so ein Kampfeinsatz nicht statt - die Gefallenen wurden daher in aller Stille und unter Angabe falscher Todesursachen beigesetzt. Zur Würdigung der Opfer blieb nur die Möglichkeit einer kollektiven Auszeichnung der gesamten Division bei gleichzeitiger Verschleierung der Hintergründe. Nach inoffiziellen Informationen traf sich der Verteidigungsminister nach dem Festakt hinter verschlossenen Türen

sischer Seite verwendet, um die östlichen und südlichen Teile der Ukraine, in denen ein großer Teil der Bevölkerung Russisch spricht, als nicht zur Ukraine gehörig zu markieren.

Michail Polikarpov: Oborona Donbassa. Igor' Strelkov - užas banderovskoj chunty! (Die Verteidigung des Donbass. Igor' Strelkov - der Schrecken der Bandera-Junta!), Moskau 2014, http://lobanizdat.livejournal.com/22694.html, 17. April 2015.

48 https://ipolk.t30p.ru/post/Strelkov-neveroyatno-pohozh-na-Suvorova.aspx, 17. April 2015 Aleksandr Arkad'evič Suvorov (1804-1882) führte alle Adels- und Ehrentitel seines Großvaters und hatte hohe Militärkommandos inne.

Siehe zum Beispiel das Video „Geroj Novorossii Igor’ Strelkov“ („Der Held Neurusslands Igor’ Strelkov“), https://www.youtube.com/watch?v=zKtDyMkLfWw, 17. April 2015. http://vz.ru/news/2014/8/20/701216.html, 17. April 2015.

51 https://www.youtube.com/watch?v=BtOQPQwalvA. Vgl. die Diskussion in www.echo.msk. ru/blog/elaev/1387152-echo, 17. April 2015. 
mit den Witwen und Müttern der gefallenen Soldaten. ${ }^{52}$ Die Ordensverleihung macht einmal mehr deutlich, wie vielfältig adaptierbar Heldenfiguren für die Bedürfnisse der jeweiligen Gegenwart sind und wie Suvorov in Vergangenheit und Gegenwart dafür herhalten musste, die wahren Verhältnisse zu verschleiern.

\section{Abbildungsnachweise}

Abb. 1: $\quad$ V. A. Durov: Russkie i sovetskie boevye nagrady [Russische und sowjetische Militärauszeichnungen], Moskau 1990, S. 80.

Abb. 2-4, 6: Klaus Waschik / Nina Baburina / Konstantin Kharin: Russische und sowjetische Plakatkunst [Internetprojekt des Lotman-Instituts für russische Kultur an der Ruhr-Universität Bochum 20012014], http://www.russianposter.ru.

Abb. 5, 7: http://www.plakaty.ru.

Abb. 8: $\quad$ V. A. Durov: Russkie i sovetskie boevye nagrady [Russische und sowjetische Militärauszeichnungen], Moskau 1990, S. 82.

Abb. 9: $\quad$ https://ru.wikipedia.org/wiki/Орден_Суворова_(Россия).

52 http://by24.org/2014/08/23/russian_soldiers_widows_and_shoygy/, 17. April 2015. 